\title{
AVANÇOS TEÓRICOS E METODOLÓGICOS NA LEITURA DA AMÉRICA LATINA: CONTRIBUIÇÕES DE JOSÉ DE SOUZA MARTINS
}

\author{
THEORETICAL AND METHODOLOGICAL ADVANCES IN LATIN AMERICAN \\ INTERPRETATION: CONTRIBUTIONS BY JOSÉ DE SOUZA MARTINS
}

\author{
Júlio César Suzuki ${ }^{1}$ \\ Universidade de São Paulo, São Paulo, Brasil
}

\begin{abstract}
Resumo: José de Souza Martins é um dos mais relevantes intelectuais brasileiros que se propuseram a constituir um pensamento novo para compreender a relação entre o atraso e a modernidade que, imbricados, marcam a sociedade brasileira. Sua contribuição, no entanto, vai para muito além do território brasileiro. Assim, pretendemos discutir os aportes teóricos e metodológicos na leitura da sociedade brasileira, em José de Souza Martins, relevantes, inclusive, para a compreensão da realidade latino-americana. Com base, então, em sua biografia e obra, relacionamos preocupações que aparecem em sua construção como intelectual das ciências sociais, bem como autores e categorias que fazem parte de suas argumentações, o que lhe garante originalidade e atualidade, no bojo de um pensamento em constante reformulação e aprimoramento.
\end{abstract}

Palavras-chave: pensamento social, teoria, método, José de Souza Martins.

\begin{abstract}
José de Souza Martins is one of the most relevant Brazilian intellectuals who proposed themselves to constitute a new thinking to understand a relationship between delay and the modernity that, imbricated, mark the Brazilian society. His contribution, however, goes to beyond Brazilian territory. Thus, we intend to discuss the theoretical and methodological contributions in the reading of Brazilian society, in José de Souza Matins, relevant, including for an understanding of the Latin American reality. Based, then, in his biography and work. We relate concerns that appear in his construction as intellectual of the social sciences, as well as authors and categories that are part of his arguments, which guarantees originality and actuality, within the scope of a thought in constant reformulation and improvement.
\end{abstract}

Keywords: social thought, theory, method, José de Souza Martins.

\footnotetext{
${ }^{1}$ Graduado em Geografia (UFMT), com mestrado e doutorado em Geografia Humana (USP). Professor Doutor junto ao Departamento de Geografia da Faculdade de Filosofia, Letras e Ciências Humanas da Universidade de São Paulo e ao Programa de Pós-graduação em Integração da América Latina/USP; e pesquisador associado da Biblioteca Brasiliana Mindlin/USP. Email: jcsuzuki@usp.br. A primeira versão de escrita deste texto se deu durante nossa estadia, como Professor Convidado, na Université Rennes 2 e na Université de Pau et des Pays de l'Adour, no ano letivo 2015-2016, cuja publicação se deu no Guia Bibliográfico da FFLCH: "José de Souza Martins: percursos metodológicos de leitura da sociedade brasileira" (http://fflch.usp.br/sites/fflch.usp.br/files/Jos\%C3\%A9\%20de\%20Souza\%20Martins.pdf).
} 


\title{
1 INTRODUÇÃO
}

\author{
"A vida não é feita apenas de motivos e de impactos, mas \\ também de circunstâncias e contradições, incertezas e \\ relutâncias.” (José de Souza Martins, 2012b, p. 197)
}

José de Souza Martins é um dos mais importantes e reconhecidos cientistas sociais do Brasil. Graduado, mestre, doutor e livre-docente pela Faculdade de Filosofia, Letras e Ciências Humanas (FFLCH) da Universidade de São Paulo (USP), seu vasto corpo de publicações é reconhecido internacionalmente devido à sua importância na construção de uma leitura original da sociedade brasileira.

Tendo se dedicado densamente ao método dialético e à leitura da sociedade brasileira, ele nos brinda com uma extensa obra em que é possível apreender o longo movimento de transformações das estruturas sociais, bem como as sutilezas do irrisório, do ínfimo, porém extremamente frequente: o que se repete continuamente na vida do homem simples, o que contribui com formulações teóricas e metodológicas originais para a leitura da América Latina.

Como ocorre com os grandes intelectuais, a obra de José de Souza Martins possui um importante movimento de preocupações que se adensam, de categorias que se refinam e de temas que se ampliam e se renovam; é o que tentaremos apresentar e aprofundar em nosso debate, com base em leituras que fizemos de seus textos, cujas contribuições são facilmente verificáveis em nossas pesquisas, particularmente as de mestrado e doutorado (SUZUKI, 1996 e 2002); e algumas resenhas que publicamos de seus livros (SUZUKI, 1998; SUZUKI; MARTINS, 2015a; SUZUKI; MARTINS, 2015b). Assim, objetivamos discutir os aportes teóricos e metodológicos na leitura da sociedade brasileira, em José de Souza Matins, relevantes, inclusive, para a compreensão da realidade latino-americana.

\section{AS PRIMEIRAS REFLEXÕES E PESQUISAS}

Nascido, em 1938, em São Caetano do Sul, oriundo de uma família de operários e tendo iniciado sua atividade profissional, também, como operário, ao conhecer a Biblioteca Municipal de São Paulo Mário de Andrade, José de Souza Martins começa uma vida de leituras e de formação intelectual, em 1955, oportunidade em que escreve seu primeiro livro, 
São Caetano do Sul em quatro séculos de história (MARTINS, 1957), mesmo antes do início do seu curso Normal, realizado na cidade de Santo André, no Instituto de Educação Dr. Américo Brasiliense, entre 1958 e 1960.

Formou-se em Sociologia em 1964, um ano extremamente complicado da história política brasileira, particularmente para a Universidade de São Paulo e para a Sociologia uspiana, em que o catedrático era Florestan Fernandes e os assistentes, Fernando Henrique Cardoso, Octávio Ianni, Marialice Mencarini Foracchi e Maria Sylvia Franco Moreira, animavam debates importantes de discussão da formação da sociedade brasileira e do desenvolvimento social.

No ano seguinte, em 1965, por convite ${ }^{2}$ de Florestan Fernandes, catedrático da cadeira de Sociologia I, José de Souza Martins passa a integrar, na qualidade de auxiliar de ensino, o grupo de assistentes da cadeira de Sociologia I da Faculdade de Filosofia, Ciências e Letras da Universidade de São Paulo, permanecendo, como professor, até 2003, ano de sua aposentadoria; em que pese a continuidade de suas pesquisas e publicações, sem qualquer interrupção, até o momento atual; além da homenagem de outorga do título de Professor Emérito, em 2008, pela Faculdade de Filosofia, Letras e Ciências Humanas/USP, o nível máximo de reconhecimento que a Universidade de São Paulo realiza aos seus intelectuais.

A partir do convite de Fernando Henrique Cardoso para participar, como bolsista, da pesquisa de Luiz Pereira (também docente da cadeira de Sociologia I) sobre qualificação do operário na empresa industrial, junto ao Centro de Sociologia Industrial e do Trabalho (CESIT) da Universidade de São Paulo, José de Souza Martins, que havia sido operário por longos anos, inicia os contatos nas fábricas, os levantamentos dos processos de trabalho, as listagens de trabalhadores e as entrevistas com operários (geralmente, realizadas no período noturno).

José de Souza Martins, sobre sua seleção e participação na pesquisa coordenada por Luiz Pereira, nos dá o seguinte testemunho:

\footnotetext{
Minha indicação decorreu tanto do meu desempenho como aluno de graduação como do fato de que eu havia trabalhado em fábrica durante vários anos. Coube-me não só levantar os dados sobre estrutura e funcionamento das 9 fábricas da pesquisa, como também realizar a maior parte das extensas entrevistas preparadas por Luiz Pereira sobre a função substitutiva de escola profissional das próprias fábricas. ${ }^{3}$
}

\footnotetext{
${ }^{2}$ O convite fora feito no segundo semestre de 1964, quando, ainda, José de Souza Martins realizava o seu último ano de graduação em Sociologia.

${ }^{3}$ Testemunho fornecido por José de Souza Martins, via e-mail, em 03/04/2017.
} 
A sua dedicação ao projeto de Luiz Pereira garantiu-lhe a possibilidade de ser selecionado para continuar a desenvolver pesquisa no CESIT, para a qual apresentou um projeto de especialização (o que viria a se transformar em mestrado ${ }^{4}$ ), sob a orientação de Octavio Ianni, tendo em vista que o tema da proposta era modernização no campo.

No último ano do curso de graduação, apresentei a Octavio Ianni um projeto de pesquisa sobre ' $\mathrm{O}$ desenvolvimento agrário no Estado de São Paulo', que se desenvolveria em três regiões: Baixa Mojiana, Alto Paraíba e Alta Sorocabana. Era um estudo comparativo sobre modernização da agricultura e resistências à mudança. Concluída a pesquisa, cheguei a escrever dois artigos, que Florestan Fernandes mandou publicar na Revista do Instituto de Estudos Brasileiros, da USP, e na revista América Latina, do Centro Latinoamericano de Pesquisas em Ciências Sociais. Nesses artigos apresento minha constatação de que as populações rurais não resistiam às mudanças e à modernização, mas incorporavam as inovações tecnológicas à sua cultura agrícola tradicional. Meu trabalho dava fundamento empírico ao que Octavio Ianni vinha tratando em seus livros e artigos como crítica da razão dualista. Ele é o pai dessa ideia. Minha pesquisa, por outro lado, mostrava, pela primeira vez, a funcionalidade do atraso. O atraso não é incompatível com o desenvolvimento capitalista, mas cumpre funções no processo de acumulação. ${ }^{5}$

Assim, em 1965, José de Souza Martins realiza pesquisas exploratórias em três regiões do estado de São Paulo (Alta Sorocaba, Baixa Mogiana e Alto Paraíba), o que lhe permitiu avançar nas discussões, feitas pela Escola Sociológica de São Paulo ${ }^{6}$, acerca das relações atrasadas como uma necessidade do capital e do desenvolvimento capitalista, já que ele percebera que a modernização não elimina o tradicional, tendo em vista a existência de caipiras do Alto Paraíba que não estavam em contradição com a modernização ou com o desenvolvimento do capitalismo. "Tratava-se de reconhecer no atrasado, no anômalo, no marginal a mediação que oferece a compreensão mais rica do processo histórico e também indica o lugar histórico de bloqueios e resistências ao desenvolvimento social." (MARTINS, 1997c, p. 145)

\footnotetext{
${ }^{4}$ Somente com a reforma universitária de 1968 são criados os cursos de pós-graduação, tanto os de lato sensu, quanto os de stricto sensu, no Brasil, sendo que, por conta de acordo MEC-USAID, na década de 1960, a Universidade de São Paulo foi utilizada como locus de implantação de um protótipo para testar a viabilidade de expansão do sistema norte-americano com a divisão entre mestrado e doutorado no país, o que conduziu para que as propostas de especialização, de meados da década de 1960, fossem transformadas em mestrados, mesmo antes da promulgação da legislação de 1968. Mesmo que os primeiros doutoramentos tenham se iniciado na década de 1940 na Universidade de São Paulo, particularmente em 1942 na Faculdade de Filosofia, Ciências e Letras, somente a partir de 1970, começam os programas de pós-graduação com mestrados e doutorados.

${ }^{5}$ Testemunho fornecido por José de Souza Martins, via e-mail, em 03/04/2017.

${ }^{6}$ Sobre Florestan Fernandes e o seu significado na formação da Escola Sociológica de São Paulo, é muito elucidativa a leitura que realiza José de Souza Martins (1998), particularmente ao recuperar detalhes importantes da contribuição de Roger Bastide e Claude Lévi-Strauss na base do pensamento social e antropológico que se desenvolveu na Faculdade de Filosofia, Ciências e Letras da Universidade de São Paulo. Cabe a leitura, ainda, de A Sociologia como aventura (MARTINS, 2013), em que se adensa a discussão sobre o percurso acadêmico de José de Souza Martins, bem como sua relação com Florestan Fernandes, além do debate de suas posições políticas e teórico-metodológicas.
} 
Este debate da relação entre o tradicional e o moderno vai aparecer densamente em sua obra, como se explicitou, por exemplo, em Capitalismo e tradicionalismo (MARTINS, 1975), de 1975, um livro que reúne textos, sobretudo, do final da década de 1960 e início dos anos 1970; bem como em A sociabilidade do homem simples (MARTINS, 2012a), publicado em 2008; como uma forte crítica à leitura dualista da sociedade brasileira.

A participação na pesquisa de Luiz Pereira, com foco na industrialização de São Paulo, e, sobretudo, a pesquisa na de Maurício Vinhas de Queiroz (docente do Instituto de Ciências Sociais da Universidade do Brasil, atual Universidade Federal do Rio de Janeiro), acerca dos grupos econômicos do Brasil, em muito contribuíram, já no início da ditadura militar, quando já havia perseguição de professores, como foi o caso de Fernando Henrique Cardoso e Octavio Ianni, para que José de Souza Martins pudesse rapidamente defender sua dissertação de mestrado, por indicação e sob a orientação, em definitivo, de Florestan Fernandes, com a substituição do tema original da modernização no campo para a biografia do grupo econômico liderado pelo Conde Matarazzo (MARTINS, 1966), cuja publicação em formato de livro (MARTINS, $1967^{7}$ ) acontece já no ano seguinte. (MARTINS, 2012b):

\begin{abstract}
Em virtude do cenário repressivo e da possibilidade da cassação de professores e eventual extinção do grupo aglutinado em torno de Florestan Fernandes, Florestan me chamou, avaliou quanto tempo levaria para concluir o mestrado (que se chamava especialização) e entendeu que era demora arriscada. Perguntou-me se tinha outro trabalho que pudesse ser aproveitado no mestrado. Por indicação de Fernando Henrique, eu me engajara como pesquisador no projeto de Mauricio Vinhas de Queiroz, da Universidade do Brasil (atual Federal do Rio de Janeiro), sobre a formação dos grupos econômicos no Brasil. Enquanto aluno de graduação, eu trabalhara durante dois anos nessa pesquisa, elaborando monografias sobre 11 grupos econômicos, brasileiros e estrangeiros instalados no Brasil. Sugeri-lhe que o relatório sobre o grupo Matarazzo poderia ser ampliado e reformulado para uma dissertação de emergência, como ele me pedia. E foi o que fiz. Daí resultou o livro "Empresário e Empresa na Biografia do Conde Matarazzo", publicado pelo Instituto de Ciências Sociais da Universidade Federal do Rio de Janeiro. Os materiais da pesquisa sobre o campo seriam diluídos em artigos. ${ }^{8}$
\end{abstract}

Para a tese de doutorado, José de Souza Martins planejou retomar a pesquisa sobre a modernização do campo, mas, novamente, por conta das dificuldades impostas à vida universitária uspiana pela ditadura militar, foi obrigado, na oportunidade por indicação e sob a orientação de Luiz Pereira (MARTINS, 2012b), a retomar a pesquisa feita sobre São Caetano do Sul (MARTINS, 1957), com os novos instrumentais analíticos alcançados durante a formação junto à Escola Sociológica de São Paulo, e defender a tese $A$ comunidade na

\footnotetext{
${ }^{7}$ A dissertação de José de Souza Martins, em 1973, teve uma segunda publicação em livro, pela editora Hucitec, com alteração do título para Conde Matarazzo - O empresário e a empresa.

${ }^{8}$ Testemunho fornecido por José de Souza Martins, via e-mail, em 03/04/2017.
} 
sociedade de classes: estudo sociológico sobre imigrante italiano e seus descendentes no subúrbio de São Paulo (núcleo colonial de São Caetano) (MARTINS, 1970), cuja publicação, como livro, acontece em 1973 (MARTINS, 1973):

\begin{abstract}
No doutorado, com a cassação de Florestan, de Fernando Henrique e de Octavio Ianni o problema se complicou. Eu havia planejado e realizado uma extensa pesquisa sobre modernização no campo, no Alto e Médio Paraíba, duas regiões polares, com níveis bem desiguais de desenvolvimento econômico e social. Fiz a pesquisa por amostragem, usando como referência o levantamento aerofotogramétrico da região. Foi a primeira (e, provavelmente, a única fez que no Brasil se utilizou a aerofotogrametria para definição de uma amostra de pesquisa sociológica. Usei o Arquivo Aerofotogramétrico aí da Geografia. Tive que desenvolver uma metodologia de campo que me permitisse corrigir as distorções da sobreposição de imagens própria desse tipo de levantamento. Concluída a pesquisa, cuja análise me tomaria largo tempo, tive que deixá-la de lado e trabalhar sobre uma de minhas pesquisas paralelas, sobre o Núcleo Colonial de São Caetano para fazer meu doutorado.
\end{abstract}

As pesquisas feitas por José de Souza Martins até o início da década de 1970 lhe permitiram acumular instrumentais teóricos e metodológicos que se desdobram densamente na sua obra $O$ cativeiro da terra.

\title{
3 SÍNTESES DE UMA OBRA MESTRA: O CATIVEIRO DA TERRA
}

As discussões iniciadas e desenvolvidas nos primeiros textos de José de Souza Martins vão lhe permitir compor debate extremamente maduro e esclarecedor em $O$ cativeiro da terra (MARTINS, 2013 [1979]), retomando e aprofundando análises iniciadas sobre o regime de colonato, presente em sua tese de doutorado, bem como o da industrialização brasileira, inserido em várias de suas discussões, mas, particularmente, em sua dissertação de mestrado.

Lançada pela primeira vez em 1979, a obra foi composta exclusivamente por artigos escritos e reunidos por José de Souza Martins, guardando, em grande medida, o seu caráter de coletânea, em que pesem repetições de discussões que apareciam em alguns de seus capítulos. No entanto, na edição de 2010, o texto passou por uma significativa revisão, permitindo, o que pode parecer surpreendente para uma contribuição no nível que se impôs já no momento de sua primeira edição, estabelecer maior coesão textual, com a supressão de repetições e adição de novos debates, como a diferenciação na forma de inserção do trabalho italiano e espanhol na agricultura cafeeira paulista.

Em $O$ cativeiro da terra, o cerne do debate está na transição do trabalho escravo ao trabalho livre, em que a terra se constitui em instrumento fundamental de entesouramento,

\footnotetext{
${ }^{9}$ Testemunho fornecido por José de Souza Martins, via e-mail, em 03/04/2017.
} 
além de a abolição escravista significar possibilidades importantes de liberação da riqueza originada da acumulação primitiva que contribuíram, em grande medida, para o início da industrialização brasileira, por mais que ela estivesse, também, ancorada no uso de recursos oriundos da atividade comercial.

Para José de Souza Martins, o desenvolvimento da indústria brasileira ficou, também, determinado pela transição do trabalho escravo ao trabalho livre, a partir da mediação da propriedade e da renda, e não pelo capital e pelo lucro nos termos clássicos, particularmente do que ocorrera na Inglaterra, já que a propriedade da terra, associada ao regime de trabalho livre, mas não somente assalariado, possibilitava a extração de renda por meio do trabalho do imigrante colono, garantindo assim a produção não só de café, mas principalmente de fazendas de café, além de uma quantidade exorbitante de mais-valor, que seria empregada não só na reprodução dos cafezais, mas nos bancos e indústrias brasileiros.

Uma categoria fundamental da tradição marxista, por mais que tão pouco utilizada, foi-lhe extremamente importante, a de renda capitalizada, pois o escravo, bem como a terra, ambos não resultantes do trabalho humano e social, portanto sem valor, possuem preço. Assim, funcionam como se fossem resultantes do processo de produção, na qualidade de mercadorias no mundo capitalista, mas não deixam de ser só e unicamente formas de propriedade, para as quais se paga um tributo social, a renda, a qual, então, funciona como se capital fosse, razão pela qual é denominada de renda capitalizada; em que pese, ainda, ter outra semelhança fundamental com o processo capitalista, a de objetivar o alcance do lucro médio.

Por mais que a submissão do trabalho se efetivasse em moldes não capitalistas, tanto a do escravo africano, quanto a do colono, o que conduzia para um processo produtivo não capitalista, a circulação o era, bem como o pensamento que fundamentava o empreendimento, com foco na comercialização internacional do café.

Assim, a renda, auferida pela propriedade de escravos ou de terras, era manejada como se fosse lucro. Mediada pela noção de lucro médio, estabelecia-se como renda capitalizada, primeiramente do escravo e, depois, com a abolição da escravidão, da terra: "A renda, até então capitalizada no escravo, tornava-se renda territorial capitalizada. Se no regime sesmarial $^{10}$, o da terra livre, o trabalho tivera que ser cativo; num regime de trabalho livre a terra tinha que ser cativa [...]." (MARTINS, 2013 [1979], p. 47, grifo no original).

\footnotetext{
${ }^{10}$ Regime ou sistema de Sesmaria se constitui, em Portugal, como instrumento jurídico para a reconquista das terras ocupadas pelos mouros, a partir da Lei das Sesmarias de 1375, tomando como preceito a necessidade de pagamento de dízimo, a concessão de pequenas frações de terra em caráter vitalício, a obrigatoriedade de
} 
A propriedade da terra possibilitava, então, ao seu proprietário extrair renda como se fosse capital, ou seja, a propriedade da terra permitia a aquisição de ganho semelhante ao lucro advindo de atividades produtivas e garantia o desenvolvimento de um regime de trabalho nas fazendas de café que, apesar de livre, não era assalariado: o colonato. Assim, uma contradição essencial fica apontada por José de Souza Martins no conjunto desta obra: a produção de uma mercadoria, que era o café, não se dava nos moldes do capitalismo clássico, o que lhe permite desenvolver o argumento de que: "[...] o capitalismo, na sua expansão, não só redefine antigas relações, subordinando-as à reprodução do capital, mas também engendra relações não capitalistas, igual e contraditoriamente necessárias a essa reprodução [...].” (MARTINS, 2013 [1979], p. 36).

Este debate central da análise de José de Souza Martins, da transição da renda capitalizada escravista à renda capitalizada da terra, assegura um olhar completamente original na leitura da formação da sociedade brasileira, em relação a importantes obras que a precederam, com as de Gilberto Freire (2003 [1933]), Sérgio Buarque de Holanda (1995 [1936]), Roberto Cochrane Simonsen (1957 [1937]), Caio Prado Júnior (1997 [1942] e 2004 [1945]), além de outras posteriores, como as de Jacob Gorender (1992 [1978]) e Alfredo Bosi (1996 [1992]); em que pese coadunar com uma importante tradição de recusa da existência do feudalismo nas Américas, onde a primeira propriedade não é a da terra, mas a dos escravos: indígenas ${ }^{11}$ ou africanos.

No bojo, ainda, de sua análise, particularmente no que se refere à transição do trabalho escravo ao trabalho livre, José de Souza Martins aprofunda o debate, iniciado na leitura da modernização do campo, projeto que fomentou as análises presentes em seus primeiros textos, acerca da relação entre as tradicionais formas de submissão do trabalho no desenvolvimento do capitalismo. No caso em particular da transição do trabalho escravo ao trabalho livre, o que reitera inúmeras vezes José de Souza Martins é a permanência de relações de produção não capitalistas, tanto no que concerne à escravização africana, quanto à contratação de colonos na agricultura cafeeira. Se no primeiro caso não havia qualquer indício de salário, no segundo, o

produção agrícola em 5 anos e a impossibilidade de apropriação por parte de cristãos-novos (recém-convertidos ao catolicismo). No Brasil, o regime sofreu profundas alterações, tendo em vista as dificuldades de permanência nas novas terras. Assim, passou a ser hereditária a concessão de grandes extensões de terra (as capitanias hereditárias), mas mantendo-se os demais preceitos.

${ }^{11}$ Vale lembrar que, na América espanhola, a escravidão não era a forma primordial de submissão do trabalho indígena, como ocorreu no caso brasileiro até, praticamente, o último quartel do século XVII, quando Marquês de Pombal legislou contra sua permanência, em que pese ainda ter sido relevante sua prática até meados do século XIX na província de São Paulo, período em que a pujança da atividade cafeeira ainda não tinha se revelado. 
sustento principal dos imigrantes estrangeiros, os colonos, se originava dos pequenos cultivos realizados entre as leiras de café.

A substituição, no Brasil, do trabalho escravo pelo trabalho livre ${ }^{12}$ foi promovida a partir de pressões externas, advindas, sobretudo, da Inglaterra desde o início do século XIX, com negociações, ainda, com Portugal, já que se estava no final do período colonial. Após a Independência, acordos foram realizados com o Brasil para por fim ao tráfico africano. Como eram tratados somente "para inglês ver", o tráfico negreiro continuou nas décadas seguintes, o que levou o Parlamento britânico a aprovar, em 1845, o Bill Aberdeen, legislação que permitia o aprisionamento e mesmo destruição de embarcações com indícios de tráfico negreiro.

Assim, em 1850, sem qualquer possibilidade de manter o tráfico de escravos africanos, é promulgada a Lei Eusébio de Queiroz que põe fim à atividade em seus primeiros anos de utilização, sobretudo por conta da mudança que operou em relação à definição dos juízes a julgarem os casos de contravenção legal, não mais das comarcas dos indiciados, mas de outras, em geral distantes, o que assegurou maior isenção nos julgamentos.

O fim do tráfico negreiro estava relacionado à criação de mecanismos que pudessem garantir abundância de mão de obra nas fazendas de café, que eram os grandes investimentos, e mais lucrativos, do período da abolição. Conforme explicita José de Souza Martins (2013 [1979]), formar fazendas era mais importante, inclusive, que a colheita dos frutos de café, realizando-se como um importante momento de formação do capital ou acumulação primitiva (MARTINS, 1997b).

Um desses mecanismos legais que permitiram a presença do trabalhador imigrante na agricultura cafeeira, o mais importante, inclusive, foi a Lei $\mathrm{n}^{\circ} 630$, de 1850 , conhecida como Lei de Terras, que legitimara a propriedade da terra subordinada à sua compra, por mais que a comercialização de terras já existisse desde o século XVIII e anterior.

A dominação do trabalhador imigrante - que não podia mais, como se deu nos primeiros anos de imigração custeada pelos fazendeiros, se fazer com o uso da força, similar, em grande medida, a que era utilizada para a submissão dos escravos africanos - requereu um novo ingrediente, principalmente após o início da subvenção estatal do processo imigratório, a

\footnotetext{
${ }^{12}$ Regime de trabalho em que não se identifica à submissão do trabalhador por meio da escravidão, tendo se iniciado, no Brasil, desde o início do período colonial, em produções de alimentos complementares à reprodução social e econômica das fazendas, mas com forte expansão principalmente a partir do processo imigratório realizado na segunda metade do século XIX.
} 
dominação ideológica ${ }^{13}$. É, então, conformada (sobretudo com o uso da história, bastante alterada, de formação do grupo econômico Matarazzo, como se fosse a de um migrante pobre, Francisco Matarazzo, que, a partir do seu esforço pessoal, consegue construir um império) uma ideologia do trabalho.

Assim, $O$ cativeiro da terra representa obra fundamental na leitura da sociedade brasileira, particularmente no que se refere à construção de relações fundamentais para a compreensão de processos sociais mediados pela propriedade, trabalho e capital, mesmo em casos que incorporem sua formação, anterior ou contemporânea à sua reprodução ampliada; situações em que a produção de relações não capitalistas se coloca no bojo do modo de produção capitalista com maior ou menor expressão.

\section{CAMPONESES E INDÍGENAS NO FAZER SOCIOLÓGICO DE MARTINS}

A partir de inúmeras experiências com camponeses e indígenas, em momentos de formação intelectual de agentes de pastoral e lideranças sociais, pelo Brasil todo, por demanda da Comissão Pastoral da Terra, José de Souza Martins desenvolve uma pedagogia muito peculiar, chamada de pedagogia investigativa, que, marcada por diálogo profundo entre sujeitos, não só modifica o que está na posição de aprendiz, mas também transforma o que ocupa a posição de professor (MARTINS, 1997b):

Procurei desenvolver uma técnica que se poderia chamar de pedagogia investigativa, em que o pesquisador desencadeia a investigação a partir das perguntas que o grupo estudado lhe faz, perguntando através de respostas para obter novas perguntas. Deixando-se interrogar e, assim, transformando-se em objeto de indagação, de deciframento do mundo de onde vem e de que faz parte, mundo que vitima esse tipo de população; mundo cuja lógica e cujas relações sociais dilaceram e condenam o mundo do camponês e do índio. Trata-se de um modo de conhecer através da vontade de conhecer e de se conhecer da própria população estudada. Desse modo é possível fazer com que o grupo estudado formule por meio de suas indagações a compreensão que tem dos acontecimentos de que é protagonista e da situação em que vive e assim exponha também seu modo de compreender e de conhecer - seu modo de produzir conhecimento, os parâmetros e critérios de sua consciência social. As perguntas que o pesquisador precisa e pode fazer, ao grupo cuja situação estuda, vem na sequência de suas respostas perguntativas, a partir das chaves de indagação e de explicação que os membros do grupo já lhe ensinaram. (MARTINS, 1997b, p .14)

\footnotetext{
${ }^{13}$ Sobre a dominação ideológica que se estabelece no modo de produção capitalista, é muito instigante e divertida a análise sobre o Tio Patinhas em Sobre o Modo Capitalista de Pensar (MARTINS, 1978).
} 
As mais de três décadas de viagens pelo país, bem como as inúmeras leituras feitas sobre os conflitos no campo, renderam-lhe um enorme aprendizado da diversidade social em que se encontram os camponeses e indígenas, o que lhe permitiu escrever inúmeros textos, apresentados em conferências, publicados em formato de artigos e, por fim, organizados em formato de livros.

No bojo deste importante momento de reflexão, encontram-se, principalmente, Expropriação e violência (MARTINS, 1980), Os camponeses e a política no Brasil (MARTINS, 1981), A militarização da questão agrária no Brasil (MARTINS, 1984), A reforma agrária e os limites da democracia na Nova República (MARTINS, 1986a), Não há terra para plantar neste verão (MARTINS, 1986b), Caminhada no chão da noite (MARTINS, 1989), A chegada do estranho (MARTINS, 1993), O Poder do Atraso ${ }^{14}$ (MARTINS, 1994); Exclusão social e a nova desigualdade (MARTINS, 1997a), Fronteira (1997b), A sociedade vista do abismo (MARTINS, 2002), O sujeito oculto (MARTINS, 2003b) e Reforma agrária - O impossível diálogo (MARTINS, 2000), cujos debates permitem aprofundar categorias, como as de terra de trabalho e terra de negócio; e relações extremamente importantes, como a de sujeição da renda ao capital; além de críticas fundamentais, como a de necessidade de superar o uso da categoria exclusão como panaceia para explicar todas as formas de subalternização, pois, em última instância, a exclusão só existe como formas precárias, subalternas e marginais de inclusão, ou seja, extremamente perversas.

No movimento deste longo percurso intelectual de mais de duas décadas de publicações, além de uma importante mudança em relação à leitura sobre as ações da Comissão Pastoral da Terra e dos movimentos sociais no campo, já em meados da década de 1980, é possível identificar uma importante alteração na discussão dos sujeitos no campo, em que uma dimensão mais antropológica se define, marcada pela valorização da categoria de temporalidades históricas, centro da análise presente em Fronteira (MARTINS, 1997b), cujo diálogo com Henri Léfèbvre é bastante significativo.

\section{DA FRENTE DE EXPANSÃO E PIONEIRA À FRONTEIRA}

\footnotetext{
${ }^{14}$ Republicado, com inclusão de novos capítulos, como A política do Brasil; lúmpen e místico (MARTINS, 2011a).
} 
Em Fronteira (MARTINS, 1997b), José de Souza Martins retoma debates importantes presentes em outros de seus textos, pois, como é próprio dos grandes autores, marcados, geralmente, pelo aprimoramento de suas categorias de análise, os novos instrumentais se renovam para ler a realidade cambiante, incessantemente em transformação; já que, quando a realidade se transforma, a teoria que se propõe a explicá-la não pode permanecer inalterada.

Fronteira revela muito dessa difícil relação existente entre teoria e real. É claro que não para o leitor preocupado apenas com a publicação mais recente; desinteressado em relação ao movimento presente num percurso intelectual que nos revela muitos dos dilemas e dificuldades enfrentados no trilhar do aprofundamento teórico e metodológico.

Em Fronteira, José de Souza Martins (1997b) analisa a região de conflitos que se estabelece entre os grupos indígenas e a sociedade nacional; de separação entre Cultura e Natureza, entre homem e animal. Dessa forma, apresenta-se como “[...] lugar privilegiado da observação sociológica e do conhecimento sobre os conflitos e dificuldades próprios da constituição do humano no encontro de sociedades que vivem no limite e no limiar da História [...]" (MARTINS, 1997b, p.12).

A figura central dessa região de conflitos é a vítima. O raptado, em “A captura do Outro - O rapto de mulheres e crianças nas fronteiras étnicas do Brasil"; o escravo por dívida, em "A reprodução do capital na frente pioneira e o renascimento da escravidão"; o excluído da pesquisa sociológica - a viúva, a divorciada, a abandonada pelo marido, a mãe solteira ou a criança que fica em casa enquanto os pais estão trabalhando -, em "Regimar e seus amigos A criança na luta pela terra e pela vida"; os camponeses e indígenas, em "O tempo da fronteira - Retorno à controvérsia sobre o tempo histórico da frente de expansão e da frente pioneira"; são todos vítimas na fronteira.

Tal posição, acerca da figura central dessa região, é bastante diferente do que se revelava no texto "Frente Pioneira: Contribuição Para Uma Caracterização Sociológica", originalmente de 1971, presente em Capitalismo e tradicionalismo (MARTINS, 1975), em que José de Souza Martins compreendia a fronteira como frente de expansão e frente pioneira, sendo que a figura central da primeira seria o ocupante ou posseiro e da segunda, o empreendedor econômico.

Se por um lado, as duas frentes distinguir-se-iam, ainda, por ser a de expansão fundada na economia do excedente ${ }^{15}$, nas condições de vida dos seus moradores, reguladas pelo grau

\footnotetext{
${ }^{15}$ Segundo José de Souza Martins (1975, p.45), “[...] a economia dessa faixa [, estabelecida entre a fronteira demográfica e a fronteira econômica que avançam distintamente, sendo que a primeira é antecessora da segunda,] não pode ser classificada como economia natural, pois dela saem produtos que assume valor de troca
} 
de fartura, e no uso privado das terras devolutas, enquanto a frente pioneira, na economia de mercado, nas condições de vida dos seus moradores, reguladas pelo grau de riqueza, e na mercantilização da terra (sua aquisição através da compra e venda).

A fronteira, por outro, põe-se não mais como locus de temporalidade única, em que há características tão bem definidas, com a presença apenas de uma figura central, mas sim como a coexistência de temporalidades diferenciadas, historicamente desiguais, convivendo no mesmo tempo cronológico.

A superação da concepção de temporalidade única fica muito bem expressa no trecho que segue:

[...] a linha de povoamento avança antes da linha de efetiva ocupação econômica do território. Quando os geógrafos falam de frente pioneira, estão falando dessa fronteira econômica. Quando os antropólogos falam de frente de expansão, estão geralmente falando da fronteira demográfica. Isso nos põe, portanto, diante de uma primeira distinção essencial: entre a fronteira demográfica e a fronteira econômica há uma zona de ocupação pelos agentes da 'civilização', que não são ainda os agentes característicos da produção capitalista, do moderno, da inovação, do racional, do urbano, das instituições políticas e jurídicas etc.

É possível, assim, fazer uma primeira datação histórica: adiante da fronteira demográfica, da fronteira da 'civilização', estão as populações indígenas, sobre cujos territórios avança a frente de expansão. Entre a fronteira demográfica e a fronteira econômica está a frente de expansão, isto é, a frente de população não incluída na fronteira econômica. Atrás da linha da fronteira econômica está a frente pioneira, dominada não só pelos agentes da civilização, mas, nela, pelos agentes da modernização, sobretudo econômica, agentes da economia capitalista (mais do que simplesmente agentes da economia de mercado), da mentalidade inovadora, urbana e empreendedora. Digo que se trata de uma primeira datação histórica porque cada uma dessas faixas está ocupada por populações que, ou estão no limite da História, como é o caso das populações indígenas, ou estão inseridas diversamente na História, como é o caso dos não-índios, sejam eles camponeses ou empresários.

Cada uma dessas realidades tem o seu próprio tempo histórico, se considerarmos que a referência à inserção ou não na fronteira econômica indica também diferentes níveis de desenvolvimento econômico que, associados a níveis e modalidades de desenvolvimento do modo de vida, sugerem datas históricas distintas e desencontradas no desenvolvimento da sociedade, ainda que contemporâneas. E não me refiro apenas à inserção em diferentes etapas coexistentes do desenvolvimento econômico. Refiro-me sobretudo às mentalidades, aos vários arcaísmos de pensamento e conduta que igualmente coexistem com o que é atual. E não estou falando de atraso social e econômico. Estou falando da contemporaneidade da diversidade. Estou falando das diferenças que definem seja a individualidade das pessoas, seja a identidade dos grupos.

Essa distinção não é conceitual nem é classificatória, ao contrário do que entendem diferentes pesquisadores que trataram da fronteira a partir do surto expansionista de 1964. Nesse equívoco repousa a controvérsia sobre o tempo histórico da frente de expansão e o tempo histórico da frente pioneira, pois não se reconhece que o tempo histórico de um camponês dedicado a uma agricultura de excedentes é um. Já o tempo histórico do pequeno agricultor próspero, cuja produção é mediada pelo capital, é outro. E é ainda outro o tempo histórico do índio

na economia de mercado. Trata-se de uma economia do excedente, cujos participantes dedicam-se principalmente à própria subsistência e secundariamente à troca do produto que pode ser obtido com os fatores que excedem às suas necessidades [...]" [grifo no original]. 
integrado, mas não assimilado, que vive e se concebe no limite entre o mundo do mito e o mundo da História. Como ainda é inteiramente outro o tempo histórico do pistoleiro que mata índios e camponeses a mando do patrão e grande proprietário de terra: seu tempo é o do poder pessoal da ordem política patrimonial e não o de uma sociedade moderna igualitária e democrática que atribui à instituição neutra da justiça a decisão sobre os litígios entre seus membros. A bala de seu tiro não só atravessa o espaço entre ele e a vítima. Atravessa a distância histórica entre seus mundos, que é o que os separa. Estão juntos na complexidade de um tempo histórico composto pela mediação do capital, que junta sem destruir inteiramente essa diversidade de situações. (MARTINS, 1997b, p. 157-159)

A concepção de uma temporalidade única é, então, superada. Não é mais a frente de expansão somente momento de gênese da frente pioneira, mas com esta divide características. Compreende-se, então, que há um continuum, como afirmara Henri Léfèbvre (1971), com sobreposição de características e presença de resíduos. Em última instância, frente de expansão e frente pioneira revelam-se como faces diferentes de uma mesma realidade, a fronteira. Tanto que José de Souza Martins (1997b) passa a reconhecer que não há duas frentes, mas sim duas perspectivas analíticas, uma realizada pelos geógrafos, a da frente pioneira, e a dos antropólogos, a de frente de expansão:

\begin{abstract}
Os estudiosos do tema da fronteira no Brasil, quando examinaram a literatura pertinente, se deparam com duas concepções de referência, através das quais os pesquisadores têm procurado dar um nome específico a essa realidade singular que é o objeto de sua investigação. Os geógrafos, desde os anos quarenta, importaram a designação de zona pioneira para nomeá-la, outras vezes referindo-se a ela como frente pioneira.

Os antropólogos, por seu lado, sobretudo a partir dos anos cinquenta, definiram essas frentes de deslocamento da população civilizada e das atividades econômicas de algum modo reguladas pelo mercado, como frentes de expansão [...]. A designação de frentes de expansão, que o próprio Ribeiro havia formulado, tornou-se de uso corrente, até mesmo entre antropólogos, sociólogos e historiadores que não estavam trabalhando propriamente com situações de fronteira da civilização. Ela expressa a concepção de ocupação do espaço de quem tem como referência as populações indígenas, enquanto a concepção de frente pioneira não leva em conta os índios e tem como referência o empresário, o fazendeiro, o comerciante e o pequeno agricultor moderno e empreendedor. (MARTINS, 1997b, p. 151-152)
\end{abstract}

Dessa forma, a fronteira supera as noções de frente de expansão e de frente pioneira, tal qual se encontram no texto primeiro de José de Souza Martins (1975), em que se discute a problemática da expansão da sociedade nacional sobre terras tradicionalmente ocupadas pelos indígenas, naquele momento nomeadas como sociedade capitalista e sociedade tribal.

A mudança terminológica, na análise da expansão da sociedade nacional, está relacionada a uma significativa alteração da perspectiva de interpretação. Em "Frente Pioneira: Contribuição Para Uma Caracterização Sociológica”, se, por um lado, prepondera uma leitura socioeconômica da expansão da sociedade capitalista em relação à sociedade tribal, como se revela muito claramente no trecho que segue: 


\begin{abstract}
A frente pioneira exprime um movimento social cujo resultado imediato é a incorporação de novas regiões pela economia de mercado. Ela se apresenta como fronteira econômica. Compreendê-la como tal, no entanto, implica em considerar que, no caso brasileiro, a fronteira econômica não coincide, necessariamente, com a fronteira demográfica (via de regra aquela está aquém desta). A faixa entre uma e outra, embora sendo povoada (ainda que com baixos índices de densidade demográfica), não constitui uma frente pioneira e não constitui basicamente porque a sua vida econômica não está estruturada primordialmente a partir de relações com o mercado. (MARTINS, 1975, p. 45)
\end{abstract}

Por outro, em Fronteira, prepondera uma leitura antropológica da expansão da sociedade nacional, como se percebe quando José de Souza Martins (1997b) identifica a vítima como figura privilegiada de análise dessa realidade singular.

No entanto, mesmo com tantas superações, permanece comum, nas duas análises uma acerca da frente de expansão e da frente pioneira; a outra, da fronteira -, a interpretação de que a expansão da sociedade nacional se estabelece com base em relações sociais não tipicamente capitalistas, com a instauração da propriedade privada da terra, ou seja, a mediação da renda capitalizada entre o produtor e a sociedade. É o que reconhece José de Souza Martins (1997b, p.99) quando afirma que não ocorre, na fronteira, somente a reprodução ampliada do capital, mas também a acumulação primitiva: “[...] $A$ expansão territorial do capital não podia depender do capital propriamente dito, atraído para setores mais lucrativos, restabelecendo-se mecanismos e processos de acumulação primitiva [...]." ([grifo no original).

A acumulação primitiva põe-se, então, como momento fundamental da expansão da sociedade nacional, sobretudo porque, como identificou José de Souza Martins, fundado em observação de Alistair Hennessy, o Brasil, como parte das sociedades latino-americanas, “[...] ainda se encontra naquele estágio de sua história em que as relações sociais e políticas estão, de certo modo, marcadas pelo movimento de expansão demográfica sobre terras 'não ocupadas' ou 'insuficientemente' ocupadas [...].” (MARTINS, 1997b, p. 147).

No entanto, o Brasil não é mais um país com a mesma dinâmica que possuía no limar da década de 1970, tendo em vista a acentuada melhoria dos meios de transporte e de comunicação, mesmo que, em grande medida, de forma bastante desigual em termos regionais. No entanto, nem tudo é aceleração. Há resíduos que permanecem de outros tempos, sobretudo nos extremos rincões do país. E o que se percebe claramente quando se anda pelo interior da Amazônia ou do Nordeste, em que a permanência do rural, na constituição de aglomerados urbanos, é extremamente marcante. Assim, é facilmente identificado um tempo lento que subjaz a essas realidades concretas, diferente do que se estabelece no Centro-Sul, 
cujos aglomerados urbanos passam, cada vez mais rapidamente, pela aceleração temporal, marcada pela modernização.

Dessa forma, é necessário que a explicação do processo social, que se estabelece com a expansão da sociedade nacional, passe a se utilizar cada vez mais da categoria de fronteira ao invés das de frente de expansão e pioneira, tendo em vista ser mais adequada ao desvendamento da realidade que se estabelece, principalmente, a partir de meados da década de 1970, em que a coexistência de temporalidades históricas é mais diversa, como se discute em inúmeros textos relacionados ao cotidiano e à história nas análises de José de Souza Martins.

\section{COTIDIANO E HISTÓRIA NA SOCIABILIDADE DO HOMEM SIMPLES}

Um dos pioneiros no debate da sociologia da vida cotidiana, a partir da oferta de uma disciplina com o mesmo nome, José de Souza Martins, no momento em que a sociedade não estava mais caminhando no sentido de uma significativa transformação, mas com reiterações bastante frequentes, busca aprofundar teoricamente e instrumentalizar metodologicamente a discussão deste novo momento, em que a vida miúda das populações subalternas toma relevo. Não mais a análise das grandes estruturas sociais e processos, mas aquela da vida miúda de todo dia, a sociologia de todos. ${ }^{16}$

Debate fortemente aprofundado já em Fronteira, em que as temporalidades históricas coexistem e disputam espaços e significados, revela-se, cada vez mais densamente, a contemporaneidade anômala que perpassa a sociedade brasileira, prenhe de incoerências, paradoxos e limites; meios, segundo José de Souza Martins (2012a), privilegiados da compreensão histórica e sociológica.

A sociabilidade do homem simples está dividida em duas partes. A primeira centrada no debate da relação entre modernidade, cotidiano e história, com base em textos anteriormente publicados, no Brasil e no exterior; e a segunda, em duas entrevistas que aprofundam a discussão acerca da história e da memória na construção de uma sociologia sensível.

Neste percurso intelectual de discussão do homem simples em sua contemporaneidade anômala, mediada pelo cotidiano e pela cotidianidade (um cotidiano alienado de seus

\footnotetext{
${ }^{16}$ Entrevista com José de Souza Martins, junto à Biblioteca Municipal de São Paulo Mário de Andrade, realizada por Daisy Perelmutter, como parte integrante do Projeto de Memória Oral. Disponível em: <https://www.youtube.com/watch?v=o8u5fOJsMWo>. Acesso em 15.dez.2015.
} 
sentidos), uma das primeiras análises de José de Souza Martins está em A morte e os mortos na sociedade brasileira (MARTINS, 1983), mas principalmente em Subúrbio (MARTINS, 1992), além de A aparição do demônio na fábrica (MARTINS, 2008a) e, mais recentemente, Uma sociologia da vida cotidiana (MARTINS, 2014).

Sendo o subúrbio onde o campo e a cidade se encontram, já que o urbano, como expressão da civilidade, é incompleto e a população é, em grande medida, oriunda do campo, as pesquisas que o tomaram como área de estudo permitiram questionar a noção de progresso no bojo da modernidade, revelando suas imbricadas contradições históricas, com sujeitos anômalos e inconclusos ${ }^{17}$.

Nesta importante leitura do miúdo e do corriqueiro, revela-se, como fundamental, a compreensão dialética da história, em que se evidenciam as datações desencontradas dos tempos históricos:

[...] as relações sociais não são uniformes nem têm a mesma idade. Na realidade, coexistem relações sociais que têm datas diferentes e que estão, portanto, numa relação de descompasso e desencontro. Nem todas as relações sociais têm a mesma origem. Todas sobrevivem de diferentes momentos e circunstâncias históricas. (MARTINS, 2012a, p. 99-100)

Assim, reitera-se a compreensão de que "[...] A sociedade atual não é constituída de uma temporalidade única. O contemporâneo é a contemporaneidade dos tempos históricos, das vivências desencontradas porque situadas diferencialmente no percurso da História." (MARTINS, 2012a, p. 149).

Fundamentalmente, então, se revela a memória dos sujeitos nos desencontros da História, como importante mediação do desvendamento dos significados ocultos de falas e atos no processo social, em que uma sociologia sensível pode em muito contribuir.

Em Uma Arqueologia da Memória Social, José de Souza Martins (2011b), ao se situar num ponto específico de sua trajetória pessoal, o falecimento de seu pai, tece a rede das linhas que o compõe no contexto de migrações e de mudanças familiares e sociais, como partícipe de uma sociedade de homens simples:

A vida de aparência insípida transcorria na turbulência oculta no território restrito da casa e do trabalho. Há por isso, um certo realismo fantástico na cultura e na

\footnotetext{
${ }^{17}$ Lembramos, aqui, um debate importante que realiza José de Souza Martins (1986b), em Não há terra para plantar neste verão, particularmente quando nos revela a situação do migrante - as andorinhas que voam do Nordeste para os canaviais do estado de São Paulo, no período do corte de cana -, de sujeitos fragmentados, deslocados e desencontrados com sua história e sua origem, divididos entre lá e cá, ou seja, incompletos, inconclusos, anômalos.
} 
mentalidade populares, no fluir da vida como fantasia, transcendência viva, mistérios, drama e incerteza. O irreal mostra-se inevitável na realidade dos dias e das noites, a vida como busca de sentido para o que sentido não tem. A história dos simples é a história do outro, nesse cotidiano negar-se para ser e viver, fabular para compreender e compreender-se.

É assim que o de depois começa silenciosamente muito antes na vida da gente comum que povoa esta narrativa feita de memória. Pensativos avós ensinavam a cada criança que ela não estava sozinha, que havia e há uma certa perenidade no liame que ata o destino dos que chegam agora aos que chegaram há muito. A cronologia dos simples estende-se pelo longo e lento tempo da formação da sociedade moderna, o tempo que nos junta e nos separa. Por isso, o voltar atrás para compreender o incompreensível agora e o possível adiante. Bem pensadas as coisas, é a finitude que dá sentido ao que começa, na vida e na história. Na trama de impensáveis acasos, nos encontros de inesperados desencontros, gente que vai sendo empurrada pela vida afora e pela História adentro no rumo do agora e da neblina do amanhã. No fim das contas, viver é fascinante e belo, também para aqueles que nasceram para as durezas do trabalho, as adversidades do emprego e do salário, as insuficiências do ganha-pão, as incertezas do dia-a-dia. Aqui, os anônimos têm nome, ainda que invisíveis artesãos da trama do hoje. Memórias sussurradas pelo outro que somos e que há em cada um. É assim que contam os que não contam, avós que falam pela boca dos netos, pais que falam pela boca dos filhos. Ajuntamentos da memória. Sussurros do viver sem rumo. (MARTINS, 2011b, p. 10-11)

A preocupação com o imaginário presente nos percursos migratórios de homens simples já tinha aparecido densamente em O Imaginário na Imigração Italiana (MARTINS, 2003), retomando debates importantes presentes desde sua primeira obra de 1957, São Caetano do Sul em quatro séculos de história.

No contexto de reprodução das relações sociais em que se inserem os homens simples, em que o Estado não lhes garante direitos fundamentais, como o da presença da Justiça, como uma das bases de estabelecimento de vínculos sociais, violências das mais avassaladoras podem se apresentar nas contradições das construções inacabadas de atraso e modernidade, com a presença, por exemplo, de linchamentos, um dos temas atuais estudados por Martins (2015).

$\mathrm{Na}$ seara dos encontros e desencontros do homem simples, José de Souza Martins (2008b), em busca da compreensão das contradições da contemporaneidade em suas múltiplas temporalidades, ressalta a importância da fotografia como valoroso instrumento de captura da mediação entre os mundos em que se deslocam os sujeitos.

\section{CONSIDERAÇÕES FINAIS PARA UMA OBRA EM ABERTO}

A obra de José de Souza Martins é extremamente ampla, mas densamente coerente e coesa, como tivemos a intenção de sustentar nestas poucas páginas de valorização de parte de sua importante contribuição intelectual na leitura da sociedade brasileira e latino-americana. 
Para além da realidade empírica, o método é o grande norte que alinhava as distâncias temáticas presentes em seus textos.

É a busca da historicidade presente nos processos sociais que assegura a unidade das diversas leituras e temas que compõem a sua obra, em que as contribuições de Karl Marx e Henri Léfèbvre são incontestáveis, bem como sua origem na Escola Sociológica de São Paulo.

\begin{abstract}
O que dá unidade a minha obra é a investigação da historicidade nas diferentes manifestações da vida social, isto é, a identificação das condições e fatores da mudança social e da transformação social nos diferentes âmbitos da realidade, mesmo na realidade mínima e cotidiana. Ainda quando o objeto se propõe aparentemente desprovido de historicidade, de tensão e de contradição. Percorro um caminho de busca de uma concepção do objeto que não se fragmenta em face de perspectivas metodológicas dotadas de legitimidade própria e nesse sentido discrepantes. Oriento-me pela identificação do histórica e concretamente possível e dos obstáculos e cerceamentos à sua manifestação e realização. Dou continuidade, numa perspectiva peculiar, ao que foi o centro das preocupações teóricas e empíricas da chamada 'escola sociológica de São Paulo', que teve em Florestan Fernandes o centro e a referência. A dialética, no resgate de Lefebvre, foi fundamental para dar a dimensão de conjunto aos meus livros e artigos, mesmo os artigos de jornal, que publico semanalmente. Basicamente, interrogo a história e o possível que se escondem no cotidiano, no banal, no repetitivo e nas meras formas do aparente. (MARTINS, 2012b, p. 226)
\end{abstract}

Assim, é possível salientar que a obra em aberto, ainda em seu pleno vigor, de José de Souza Martins, ao se debruçar sobre a sociedade brasileira, em dimensões das mais diversas, nos brindou com mediações teóricas e metodológicas importantes para a compreensão de situações e processos dos mais complexos da realidade social latino-americana.

\title{
8 REFERÊNCIAS
}

BOSI, Alfredo. Dialética da colonização. 3.ed. São Paulo: Companhia das Letras, 1996 [1992].

FREYRE, Gilberto. Casa-grande \& senzala; Formação da família brasileira sob o regime da família patriarcal. 48.ed. São Paulo: Global, 2003 [1933].

GORENDER, Jacob. O escravismo colonial. São Paulo: Ática, 1992 [1978].

HOLANDA, Sérgio Buarque de. Raízes do Brasil. 26.ed. São Paulo: Companhia das Letras, 1995 [1936].

LÉFÈBVRE, Henri. Au-delà du structuralisme. Paris: Anthropos, 1971.

MARTINS, José de Souza. A aparição do demônio na fábrica; origens sociais do Eu dividido no subúrbio operário. São Paulo: 34, 2008 a. 
. A chegada do estranho. São Paulo: Hucitec, 1993.

. A comunidade na sociedade de classe; estudo sociológico sobre imigrante italiano e seus descendentes no subúrbio de São Paulo (núcleo colonial de São Caetano). 1970, 190 f. Tese (Doutorado em Sociologia), Faculdade de Filosofia, Letras e Ciências Humanas, Universidade de São Paulo. São Paulo, 1970.

. A imigração e a crise do Brasil agrário. São Paulo: Pioneira, 1973.

. A militarização da questão agrária no Brasil. Petrópolis: Vozes, 1984.

. A morte e os mortos na sociedade brasileira. São Paulo: Hucitec, 1983.

. A política do Brasil; lúmpen e místico. São Paulo: Contexto, 2011a.

. A reforma agrária e os limites da democracia na Nova República. São Paulo: Hucitec, 1986a.

. A sociabilidade do homem simples; cotidiano e história na modernidade anômala.

3.ed. São Paulo: Contexto, 2012a.

. A sociedade vista do abismo; Novos estudos sobre exclusão, pobreza e classes sociais. Petrópolis: Vozes, 2002.

. A Sociologia como aventura; memórias. São Paulo: Contexto, 2013.

. Caminhada no chão da noite; emancipação política e libertação nos movimentos sociais no campo. São Paulo: Hucitec, 1989.

Capitalismo e tradicionalismo; estudos sobre as contradições da sociedade agrária no Brasil. São Paulo: Pioneira, 1975.

. Empresário e empresa na biografia do Conde Matarazzo. Rio de Janeiro: Instituto de Ciências Sociais/Universidade do Brasil [UFRJ], 1967.

Empresário e empresa na biografia do Conde Matarazzo. Dissertação (Mestrado em Sociologia), Faculdade de Filosofia, Ciências e Letras, Universidade de São Paulo. São Paulo, 1966.

. Entrevista com José de Souza Martins. Primeiros Estudos, São Paulo, n.3, p.197-233, 2012b. Entrevista concedida à Isabel Furlan Jorge e Romulo Lelis.

. Exclusão social e a nova desigualdade. São Paulo: Paulus, 1997a.

. Expropriação e violência; a questão política no campo. São Paulo: Hucitec, 1980.

. Florestan; Sociologia e Consciência Social no Brasil. São Paulo: EDUSP, 1998.

$1997 b$

Fronteira; A degradação do Outro nos confins do humano. São Paulo: Hucitec, 
. Linchamentos; A justiça popular no Brasil. São Paulo: Contexto, 2015.

. Não há terra para plantar neste verão. Petrópolis: Vozes, 1986b.

. O cativeiro da terra. 9.ed. São Paulo: Contexto, 2013 [1979].

1994.

. O Poder do Atraso; Ensaios de Sociologia da História Lenta. São Paulo: Hucitec,

. O Imaginário na Imigração Italiana. São Caetano do Sul: Fundação Pró-Memória, $2003 \mathrm{a}$. $2003 b$.

O sujeito oculto; ordem e transgressão na reforma agrária. Porto Alegre: UFRGS,

. Os camponeses e a política no Brasil; As lutas sociais no campo e seu lugar no processo político. Petrópolis: Vozes, 1981.

. Reforma agrária - O impossível diálogo. São Paulo: EDUSP, 2000.

. São Caetano do Sul em quatro séculos de história. São Paulo: Saraiva, 1957.

. Sobre o Modo Capitalista de Pensar. São Paulo: Hucitec, 1978.

. Sociologia da fotografia e da imagem. São Paulo: Contexto, 2008b.

Sociologia e militância: entrevista. Estudos Avançados, v.11, n.31, p.137-187, 1997c. Entrevista concedida a Alfredo Bosi. 1992.

. Subúrbio; vida cotidiana e história no subúrbio de São Paulo. São Paulo: Hucitec,

.Uma Arqueologia da Memória Social; Autobiografia de um Moleque de Fábrica. Cotia: Ateliê Editorial, $2011 \mathrm{~b}$.

. Uma sociologia da vida cotidiana. São Paulo: Contexto, 2014.

PRADO JÚNIOR, Caio. Formação do Brasil Contemporâneo; colônia. 23.ed. São Paulo: Brasiliense, 1997 [1942].

. História Econômica do Brasil. São Paulo: Brasiliense, 2004 [1945].

SIMONSEN, Roberto Cochrane. História Econômica do Brasil. 3.ed. São Paulo: Nacional, 1957 [1937].

SUZUKI, Júlio César. A gênese da moderna cidade de São Paulo. 2002, 158f. Tese (Doutorado em Geografia Humana), Faculdade de Filosofia, Letras e Ciências Humanas, Universidade de São Paulo. São Paulo, 2002. 
Da frente de expansão e pioneira à fronteira: percursos de um pesquisador. Geousp; Revista da Pós-Graduação em Geografia, n.4, p.115-119, 1998. Resenha de: MARTINS, José de Souza. Fronteira; A degradação do Outro nos confins do humano. São Paulo: Hucitec, 1997.

De povoado a cidade; A transição do rural ao urbano em Rondonópolis. 1997, $204 \mathrm{f}$. Dissertação (Mestrado em Geografia Humana), Faculdade de Filosofia, Letras e Ciências Humanas, Universidade de São Paulo. São Paulo, 1996.

SUZUKI, Júlio César; MARTINS, Marcos Henrique. A sociabilidade do homem simples. Bolletino dela società Geografica Italiana, série XIII, v.VIII, fascículo 1, p.143, jan.mar.2015a. Resenha de: MARTINS, José de Souza. A sociabilidade do homem simples; cotidiano e história na modernidade anômala. 3.ed. São Paulo: Contexto, 2012.

O cativeiro da terra. Bolletino dela società Geografica Italiana, série XIII, v.VIII, fascículo 1, p.147-149, jan.-mar.2015b. Resenha de: MARTINS, José de Souza. O cativeiro da terra. 9.ed. São Paulo: Contexto, 2013.

Recebido em 19/05/2017.

Aceito em 19/07/2017.

Publicado em 21/09/2017.

DOI: 10.11606/issn.1676-6288.prolam.2016.133912 